\title{
Improving Independence Self-care of Postpartum Mother Through Transformational Leadership: Literature Review
}

\section{Meningkatkan Kemandirian Perawatan Diri Ibu Postpartum Melalui Transformational Leadership: Literature Review}

Steffy Putri Amanda, Lukv Dwiantoro

\begin{abstract}
Background: Self-care for postpartum mothers is very necessary, based on Orem's theory that humans basically have the ability to care for themselves. The way to improve mother's independence is by the influence of a leader (health worker). Transformational leadership is a leadership style that can motivate subordinates to be able to do better, in this case can be applied in improving the independence of postpartum mothers.
\end{abstract}

Objective: Provide an overview of how to improve self-care of postpartum mothers through transformational leadership.

Method: The method used in the search process using the PubMeds website, Nursing Journal Bina Husada, Diponegoro Nursing Journal. Search keywords are independence, postpartum mothers, self care.

Result: Idealized / Charismatic Influence: the influence of a leader is needed to create an ideal influence, the experience of childbirth supports the ability of postpartum mothers to perform postpartum care. Inspirational Motivation: motivation and inspiration that can provide encouragement, independent family development affects the level of mother's independence. Individualized Consideration: a nurse must be able to respect the patient's background and environment in order to create a harmonious relationship and increase the patient's confidence. Intellectual Stimulation: transformational leadership style that encourages subordinates to solve problems carefully, the higher the level of knowledge the easier it is to receive information.

Conclusion: Postpartum mother independence can be improved through transformational leadership.

Keywords: Independence, Postpartum Mother, Self Care

Afiliasi Penulis

Departemen Keperawatan Peminatan Maternitas, Universitas Diponegoro Departemen Keperawatan Peminatan Manajemen, Universitas Diponegoro

Korespondensi kepada

S.P. Amanda

steffy.amanda94@gmail.com 


\section{Intisari}

Pendahuluan: Perawatan diri secara mandiri pada ibu nifas sangat diperlukan, berdasarkan Teori Orem manusia pada dasarnya mempunyai kemampuan untuk merawat dirinya sendiri. Cara untuk meningkatkan kemandirian ibu adalah dengan adanya pengaruh seorang pemimpin (tenaga kesehatan). Kepemimpinan transformasional adalaha gaya kepemimpinan yang dapat memotivasi bawahannya untuk dapat beebuat lebih baik, dalam hal ini dapat diterapkan dalam meningkatkan kemandirian ibu nifas.

Tujuan: Memberikan gambaran terhadap cara meningkatkan kemandirian perawatan diri ibu postpartum melalui kepemimpinan transformasional.

Metode: Metode yang digunakan dalam proses pencarian dengan menggunakan website PubMeds, Jurnal Keperawatan Bina Husada, Jurnal Keperawatan Diponegoro. Kata kunci pencarian yaitu kemandirian, ibu nifas, perawatan diri.

Hasil dan Pembahasan: Idealized/Charismatic Influence: pengaruh dari seorang pemimpin sangat dibutuhkan agar menimbulkan pengaruh yang ideal, pengalaman melahirkan mendukung kemampuan ibu nifas dalam melakukan perawatan masa nifas. Inspirational Motivation: motivasi dan inspirasi yang dapat memberikan dorongan, bina keluarga mandiri berpengaruh terhadap tingkat kemandirian ibu. Individualized Consideration: seorang perawat harus mampu menghargai latarbelakang dan lingkungan pasien agar tercipta hubungan yang harmonis dan meningkatkan rasa percaya diri pasien. Intellectual Stimulation: gaya kepemimpinan transformasional yang mendorong bawahannya untuk menyelesaikan permasalahan dengan cermat, makin tinggi tingkat pengetahuan makin mudah menerima informasi.

Kesimpulan: Kemandirian ibu nifas dapat ditingkatkan melalui kepemimpinan transformasional.

Kata kunci : Kemandirian, Ibu Nifas, Perawatan Diri

\section{Pendahuluan}

Kemandirian adalah kemampuan seseorang untuk dapat menyelesaikan tugas yang sesuai dengan tahap perkembangannya (Lie, 2004). Kemandirian yang didapat oleh seseorang merupakan kumpulan selama proses belajar dalam kehidupannya, sehingga indvidu mampu berfikir dan bersikap mandiri dalam menghadapi situasi, kondisi, dan lingkungan yang terjadi dalam kehidupannya. Kemandirian menumbuhkan rasa percaya diri dan kemantapan seseorang untuk memilih jalan hidupnya (Mu'tadin, 2004).

Berdasarkan teori keperawatan Self Care Deficit yang dikemukakan oleh Dorothea Orem, manusia pada dasarnya memiliki kemampuan untuk merawat dirinya sendiri. Self care merupakan tindakan seseorang untuk menolong dirinya sendiri dalam mempertahankan hidup, kesehatan dan kesejahteraan (Tommy \& Alligood, 2006).

Perawatan diri secara mandiri pada ibu nifas sangat diperlukan, karena pada masa ini wanita mengalami banyak perubahan dalam dirinya baik fisik maupun psikologi. Hal yang harus diperhatikan dalam meningkatkan kemandirian ibu nifas adalah makanan bergizi, pencegahan terhadap infeksi, pergerakan otot untuk melancarkan peredaran darah.

Berdasarkan hasil penelitian Maharani (2012) menunjukkan bahwa pengetahuan ibu postpartum normal $57,1 \%$ masih kurang dalam hal perawatan diri, hal ini terjadi karena sebagian besar belum mendapatkan informasi kesehatan tentang perawatan diri.

Dampak yang ditimbulkan karena kurangnya informasi tentang kesehatan perawatan diri ibu postpartum adalah infeksi nifas (edometritis, 
peritonitis, mastitis), tromboembolik, tromboplebitis akibat kurang mobilisasi, hematoma vulva, depresi postpartum, postpartum blues dan psikosa nifas (Bobak, 2004 dan Maryunani, 2009).

Kemandirian ibu nifas dipengaruhi oleh berbagai macam faktor diantaranya: pengetahuan, motivasi, budaya, kepercayaan, pengalam ibu, usia ibu, dukungan keluarga, tingkat kelelahan, dan kondisi fisik ibu (Bobak, 2004; Saleha 2009).

Untuk dapat meningkatkan kemandirian ibu nifas terdapat beberapa cara yaitu: menggunakan pendekatan supportive-educative "Orem", pendekatan model "mother-baby care" (M-BC), bimbingan tehnik menyusui, kelas ibu hamil, discharge planning, dan bina keluarga mandiri (Jannah, 2013; Kristianti, 2017; Mardiatun, 2009; Tinok 2012; Vetty, 2011; Yuliana, 2007).

Secara garis besar cara untuk meningkatkan kemandirian ibu adalah dengan adanya pengaruh seorang pemimpin (tenaga kesehatan) dalam mengarahkan pasien untuk melakukan perubahan perilaku dan menselaraskan persepsi terhadap upaya peningkatan kemandirian pada ibu nifas. Menurut Bambang (2012) mengungkapkan bahwa gaya kepemimpinan sangat berpengaruh yang cukup besar dalam keberhasilan mencapai tujuan yang telah ditetapkan.

Berdasarkan penelitian Solechah (2013) menyebutkan bahwa 59,9\% adanya pengaruh antara gaya kepemimpinan transformasional terhadap motivasi kerja. Tenaga kesehatan seharusnya memiliki gaya kepemimpinan ini untuk dapat memotivasi ibu nifas agar meningkatkan kemandirian dan derajat kesehatan.

Kepemimpinan transformasional menurut O'Leary (2001) merupakan gaya yang digunakan seorang manajer untuk memotivasi bawahannya untuk berbuat lebih baik dari apa yang bisa dilakukan. Perawat sebagai konselor atau bisa disebut sebagai manajer mempunyai kesempatan untuk dapat memotivasi pasien yaitu pada ibu postpartum agar dapat meningkatkan kemandiriannya. Literature review ini memiliki tujuan untuk memberikan informasi tentang cara atau upaya meningkatkan kemandirian ibu postpartum melalui transformational leadership.

\section{Metode}

Metode yang digunakan dalam penulisan ini adalah studi literature review. Sumber pustaka yang digunakan dalam penyusunan literature review menggunakan artikel dengan proses pencarian artikel melalui PubMeds, Jurnal Keperawatan Diponegoro (JKD), Jurnal Keperawatan Bina Husada. Pencarian artikel dengan mengumpulkan tema kemandirian ibu postpartum dan transformational leadership penulis melakukan sintesa. Tahun penerbitan artikel yang digunakan untuk literature review adalah tahun 2004 sampai 2017. Kata kunci pencarian yaitu kemandirian, ibu nifas, perawatan diri.

\section{Hasil \& Pembahasan}

Hasil yang dapat dijabarkan dari pencarian artikel yang terkait dengan proses transformational leadership yang diterapkan untuk meningkatkan kemandirian ibu postpartum terangkum dalam poin-poin berikut.

\section{Idealized/Charismatic Influence}

Idealized/Charismatic Influence dapat meningkatkan kemandirian ibu, Bass (2006) menyatakan bahwa Idealized/Charismatic Influence adalah pimpinan yang mempengaruhi bawahan sehingga menimbulkan pengaruh yang ideal. Hasil penelitian Windarti (2017) menyatakan bahwa terdapat pengaruh yang signifikan antara paritas dengan perawatan mandiri, yaitu artinya bahwa pengalaman melahirkan mendukung kemampuan ibu nifas dalam melakukan perawatan masa nifas. Perempuan primipara sebagian besar kurang mampu dalam perawatan diri daripada perempuan multipara (Windarti, 2017). Berdasarkan Teori Orem menyatakan bahwa semakin bertambahnya usia pemenuhan kebutuhan self care akan semakin efektif.

\section{Inspirational Motivation}

Inspirational motivation merupakan motivasi dan inspirasi yang dapat memberikan dorongan agar seorang bawahan optimis dan antusias (Bass, 2006). Maharani (2012) mengungkapkan bahwa dukungan keluarga ibu postpartum terhadap perawatan diri adalah baik yaitu $51,8 \%$. Hal ini 


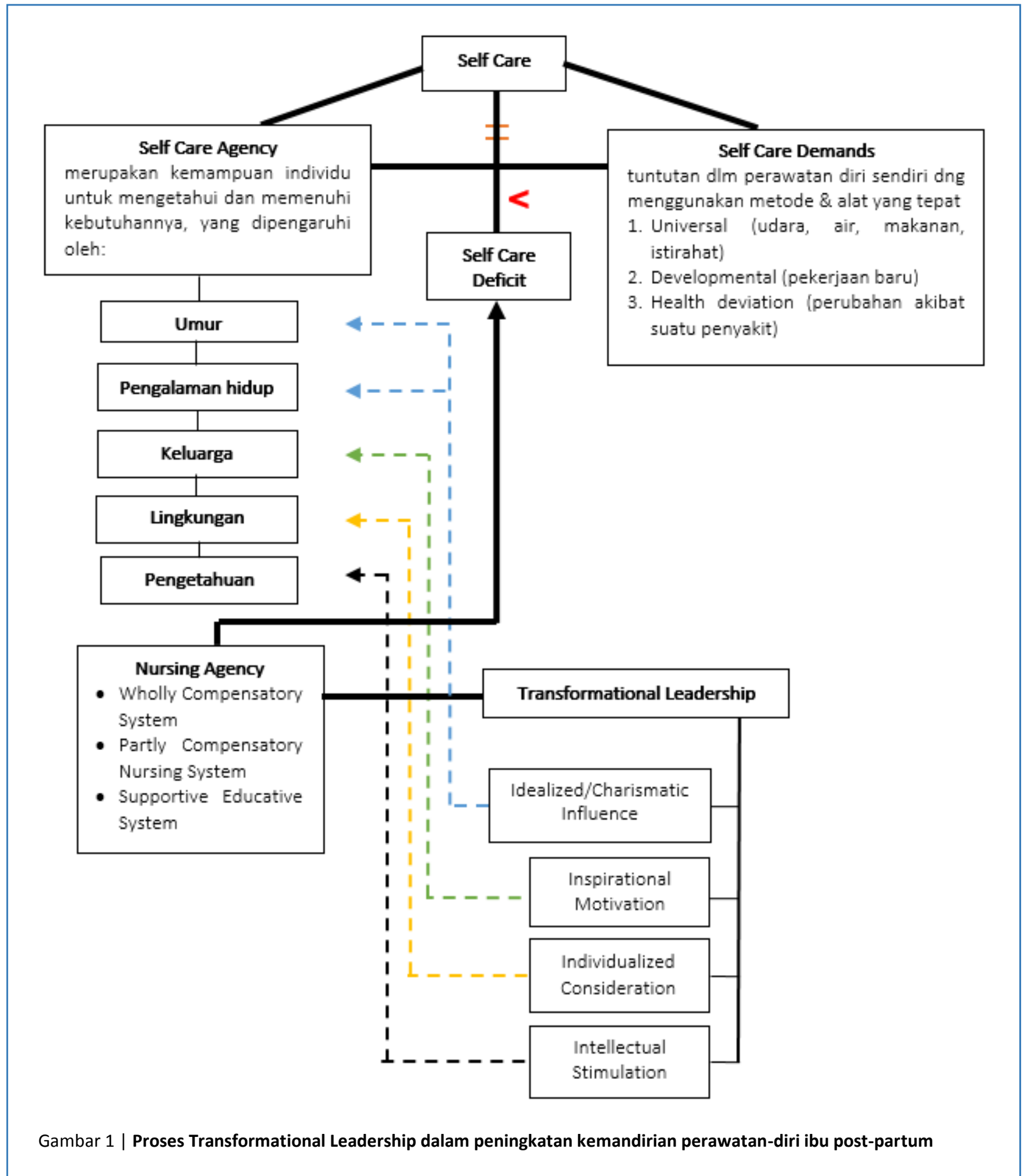

didukung oleh penelitian Jannah (2013) bahwa bina keluarga mandiri berpengaruh terhadap tingkat kemandirian.

\section{Individualized Consideration}

Masyarakat Indonesia mayoritas menggunakan kepercayaan turun temurun dan selalu diwariskan pada setiap keturunan anggota keluarganya termasuk dalam hal merawat anggota (Revida,
2011). Karakter seorang pemimpin yang mampu menghargai perbedaan individual lainnya adalah cerminan dari Individualized Consideration. Dalam lingkungan sehari-hari pengaruh keluarga sangat menentukan tingkat kemandirian ibu. Hal ini sejalan dengan pendapat Prawiroharjo (2009) faktor yang mempengaruhi paritas adalah pendidikan, pekerjaan, ekonomi, latarbelakang budaya, dan pengetahuan. Sebagai seorang 
perawat harus mampu menghargai latarbelakang dan lingkungan pasien agar tercipta hubungan yang harmonis dan meningkatkan rasa percaya diri pasien.

\section{Intellectual Stimulation}

Faktor yang mempengaruhi kemandirian ibu salah satunya adalah tingkat pengetahuan, menurut lqbal (2006) makin tinggi tingkat pengetahuan makin mudah menerima informasi. Pernyataan tersebut sesuai dengan metode self care Orem dimana tingkat pendidikan menentukan kemandirian seseorang. Didukung oleh hasil penelitian Maharani (2012) tingkat pengetahuan ibu dalam melakukan perawatan diri adalah kurang baik yaitu 57,1\%. Intellectual Stimulation merupakan gaya kepemimpinan transformasional yang mendorong bawahannya untuk menyelesaikan permasalahan dengan cermat, hal ini dapat diterapkan dalam penyelesaian masalah tingkat kemandirian ibu nifas. Perawat mendorong ibu untuk dapat menerima informasi baik melalui perawat secara langsung, media massa, elektronik, dan lain-lain sehingga ibu mampu meningkatkan intelektual dan kemandirian dalam merawat diri.

\section{Kesimpulan}

Meningkatkan kemandirian ibu postpartum merupakan sebuah tindakan yang dapat meningkatkan derajat kesehatan. Berbagai macam cara dapat dilakukan untuk dapat meningkatkan kemandirian ibu postpartum, salah satunya adalah menggunakan pendekatan kepemimpinan transformasional. Kepemimpinan transformasional memiliki beberapa komponen yang sesuai dengan teori Orem. Cara untuk meningkatkan kemandirian adalah dengan adanya peran perawat sebagai pemimpin untuk dapat memotivasi ibu nifas serta peran seorang perawat sebagai role model tindakan keperawatan yang dapat meningkatkan kemandirian ibu postpartum.

\section{Bibliografi}

1. Alligood, MR. (2006). Nursing Theories and Their Work $6^{\text {th }} E d$. Mosby. St. Louis Missouri.

2. Bambang Haryanto, 2012, Tesis, Pengaruh Gaya Kepemimpinan Transformasional dan Motivasi Kerja Terhadap Kinerja Karyawan (Studi pada Bagian Produksi PT. Gatra Mapan FM-2), Universitas
Brawijaya, Malang.

3. Bass, M. Bernard dan Riggio, E. Ronald. (2006). Transformational Leadership. Second Edition. New Jersey: Lawrence Erlbaum Associates, Inc

4. Bobak, Lowdermik, Jensen. (2004). Buku Ajar Keperawatan Maternitas, Edisi 4. Jakarta: EGC.

5. Cangara, Hafied. (2012). IImu Komunikasi. Jakarta: Rajawali Press.

6. George, J.B. (1995). Nursing Theory: The Base For Profesional Nursing Practice, Fourth Edition. Appleton and Lange: California

7. Jannah. (2013). Pengaruh Bina Keluarga Mandiri Terhadap Kemandirian Keluarga Dalam Melakukan Pemenuhan Gizi Ibu Hamil. 27 Agustus 2018.

8. Lie, Anita. (2004). Cooperative Learning. Jakarta: Grasindo.

9. Lubis, Namora. (2011). Memahami Dasar-Dasar Konseling Dalam Teori dan Praktik. Jakarta: Prenada Media Group.

10. Maharani. (2012). Faktor-Faktor Yang Berhubungan Dengan Motivasi Postpartum Normal Dalam Melakukan Perawatan Diri. 27 Agustus 2018.

11. Mardiatun. (2009). Pengaruh Pendekatan SupportiveEducative "Orem" Terhadap Peningkatan Kemandirian Ibu Nifas Dalam Perawatan Diri Selama Early Post Partum di Puskesmas Karang Taliwang Mataram Nusa Tenggara Barat. 27 Agustus 2018.

12. Mu'tadin, Z. (2004). Kemandirian Sebagai Kebutuhan Psikologi. Jakarta: Rineka Cipta.

13. O'Leary, Elizabeth . (2001). Kepemimpinan. Yogyakarta: Andi

14. Prawiroharjo, S. (2009). IImu Kebidanan. Jakarta: YBP-SP

15. Revida, E. (2011). Sistem Kekerabatan Masyarakat Indonesia. Diakses tanggal 4 September 2018 dari http://repository.usu.ac.

16. Saleha, S. (2009). Asuhan Kebidanan pada Nifas. Jakarta: Salemba Medika.

17. Solechah. (2013). Gaya Kepemimpinan Transformasional, Karakteristik Individu dan Motivasi Karyawan, Pengaruhnya Terhadap Kinerja Karyawan. 30 Agustus 2018.

18. Tinok. (2012). Kemandirian Perawatan Ibu Post Sectio Caesarea Dengan Pendekatan Discharge Planning berdasarkan Teori Self Care Orem. 27 Agustus 2018.

19. Vetty. (2013). Kemandirian Ibu Postpartum Dalam Perawatan Bayi Baru Lahir Dengan Menggunakan Pendekatan Model "Mother-Baby Care (M-BC)". 27 Agustus 2018.

20. Windarti, Yunik. (2017). Pengaruh Paritas dan Media 
Konseling Masa Nifas Terhadap Kemampuan Perawatan Mandiri Ibu Post Partum. Diakses tanggal 28 Agustus 2018.

21. Yanti, Damai dan Sundawati. (2011). Asuhan Kebidanan Masa Nifas Belajar Menjadi Bidan Profesional. Bandung: Reika Aditama. 